\title{
ANÁLISE ESPACIAL DA VIOLÊNCIA CONTRA AS MULHERES NOS ANOS DE 2012 E 2013
}

\author{
SPATIAL ANALYSIS OF VIOLENCE AGAINST WOMEN BETWEEN \\ 2012 AND 2013
}

\author{
Isabelle Frota Ribeiro Queiroz, Maria do Socorro Carneiro, Marcos Aguiar Ribeiro, Sandra \\ Maria Carneiro Flôr, Manoelise Linhares Ferreira Gomes, Eliany Nazaré Oliveira
}

Universidade Estadual Vale do Acaraú - UVA

Abstract

The violence against women is configured as a public health problem due to high morbidity and mortality rates. Thus, the use of computational tools are useful to expand and potentiate the socio-territorial space analysis to possible endangered areas to violence against women. This study aimed to analyze the geographical distribution of violence against women reported in Sobral, Ceará, in 2012 an 2013. It is ans epidemiological, descriptive, of transversal reference. The data is secondary, originated from SINAN-NET reports, after the PET-Saúde intervention for notification of violence cases registered by Women's Police Station of Sobral City. It was performed a sociodemographic characterization of the cases, with a spatial presentation of georeferencing of violence cases. From this study it was verified an increase of notifications after the intervention from PET. Besides, it was noticed the prevalence of young adult women, with ignored schooling, married or separated. The psychological and physical violence were more frequent and the most incident neighborhoods concerning the occurrence were: Sumaré, Centro, Sinhá Sabóia e Dr. José Euclides. The Geoprocessing is an important tool to analyze the territorial situation and subsidize the elaboration of plans and politics for confronting this problem and its prevention.

Key words: Violence Against Women; Epidemiology; Spatial Analysis.
Resumo

A violência contra a mulher configura-se como problema de saúde pública em virtude dos elevados índices de morbidade e mortalidade. Dessa forma, a utilização de ferramentas computacionais são úteis para ampliar $e$ potencializar a análise do espaço socioterritorial para possíveis áreas de risco de violência contra a mulher. Este estudo objetivou analisar a distribuição geográfica da violência contra as mulheres notificadas em Sobral, Ceará, nos anos de 2012 e 2013. Trata-se de um estudo epidemiológico, descritivo, de referência transversal. Os dados são secundários, originados dos registros do SINAN - NET, após a intervenção PET-Saúde para notificação dos casos de violência registrados pela Delegacia da Mulher de Sobral. A partir deste estudo, verificou-se um aumento das notificações após a intervenção realizada pelo PET. Além disso, percebeu-se a prevalência de mulheres jovens- adultas, com escolaridade ignorada, casadas ou separadas. As violências psicológicas e físicas foram mais frequentes e os bairros com ocorrência foram os com menores condições socioeconômicas, excetuando- se o centro. O Geoprocessamento é uma ferramenta importante para analisar a situação territorial e subsidiar elaboração de planos e políticas públicas para o enfrentamento desse problema e sua prevenção.

Palavras chave: Violência Contra a Mulher; Epidemiologia; Análise Espacial. 


\section{Introdução}

A violência contra a mulher configura-se, atualmente, como um problema de saúde pública em decorrência dos seus elevados índices de morbidade e mortalidade, além de estar conectada diretamente com as desigualdades de gênero ${ }^{1}$.

A interação de inúmeros fatores que atuam sobre o comportamento humano pode resultar em violência. A baixa escolaridade, as desigualdades sociais, o uso de drogas, a infraestrutura precária na comunidade parecem exacerbar esse fenômeno, aumentando o risco das mulheres que vivenciam essa situação ${ }^{2}$. Nesse contexto, a violência pode ser produto de uma construção cultural, política e religiosa pautada nas diferenças entre os sexos. Alguns autores $^{2}$ ponderam que tal construção naturalizou e legitimou a assimetria de poder justificando o domínio do homem sobre a mulher. Afirmam, ainda, que a forma mais comum da consequência da violência contra a mulher é a praticada por parceiro íntimo, a qual ocorre entre pessoas de diferentes raças, religiões, classe econômica e social.

A violência contra a mulher pode ser considerada como toda e qualquer atitude baseada em uma perspectiva de gênero, que cause morte, dano ou sofrimento nos âmbitos físico, sexual ou psicológico à mulher. Neste sentido, é produto de uma construção histórica marcada pela intersubjetividade e no encontro com a alteridade, a partir de uma demarcação de poder, de negação e de opressão às mulheres ${ }^{3}$.

A abordagem de gênero considera a diversidade dos processos de socialização de homens e mulheres, sendo que as desigualdades existentes entre os sexos determinam as consequências que impactam a vida e as relações dos seres humanos tanto no plano individual quanto no coletivo, distanciando a mulher de sua emancipação social e trazendo prejuízos para ambos os sexos 4 .

Os dados de violência contra a mulher revelam a magnitude desse fenômeno em nível mundial. Mulheres com idade entre 15 e 44 anos têm maior risco de sofrerem estupro e violência doméstica do que acidentes, contraírem câncer ou malária. No Brasil, a cada dois minutos, cinco mulheres são agredidas violentamente. Estes atos violentos resultam na perda de um ano de vida saudável a cada cinco anos de violência².

A partir da necessidade de novas medidas de controle para tentar reduzir a incidência desse agravo, foi criada a Lei no 11.340/2006, conhecida por Lei Maria da Penha a qual definiu a violência familiar como sendo aquela praticada por pessoa com laço consanguíneo ou que se considere aparentada; a violência doméstica, a praticada no espaço de convívio permanente de pessoas independente de vínculo. Essa Lei visa proteger as mulheres das diversas formas de violências, além de coibir e prevenir a violência doméstica e familiar, bem como punir os agressores ${ }^{5}$.

Visando realizar um controle mais efetivo dessa violência, diversos instrumentos vêm sendo empregados para o monitoramento e o conhecimento da distribuição desses eventos na população. A portaria de no 104 do Ministério da Saúde, publicada em 25 de janeiro de 2011 incluiu os casos de violência doméstica ou sexual na relação de doenças e agravos de notificação obrigatória no Sistema de Informação de Agravos de Notificação6.

Além disso, outras ferramentas computacionais do campo do geoprocessamento, como os Sistemas de Informações Geográficas (SIG), são úteis para a montagem de um painel socioterritorial ampliado que potencializa o olhar dos pesquisadores, gestores e trabalhadores da saúde sobre os fatores determinantes do processo de violência doméstica contra a mulher ${ }^{7}$.

A utilização do geoprocessamento na saúde pública tem-se destacado nesta área por ser capaz de contribuir para o planejamento e avaliação das ações de saúde, de forma a mapear, monitorar e disseminar as informações em saúde no âmbito do SUS, propiciando a evolução do sistema de saúde como um todo, em especial a Atenção Primária à Saúde pública, por meio de recursos que proporcionarão melhoria da qualidade da informação nesse setor ${ }^{8}$.

Tendo em vista o exposto sobre a violência contra a mulher, este estudo objetivou analisar a distribuição geográfica da violência contra as mulheres notificadas em Sobral, Estado do Ceará, nos anos de 2012 e 2013.

\section{Metodologia}

Trata-se de um estudo epidemiológico, descritivo, de referência transversal. Os estudos epidemiológicos investigam agregados humanos, coletivos ou indivíduos membros de grupos desses agregados, sempre se referindo a uma base geográfica e temporal. O caráter transversal define quando a produção do dado é realizada em um único momento no tempo (singular), como se fora um corte transversal do processo em observação. Estes estudos são de grande utilidade para realização dos diagnósticos comunitários da situação local de saúde ${ }^{9}$. 
Os dados são secundários, originados dos registros do Sistema de Informação de Agravos de Notificação- NET local (SINAN-NET), após a intervenção do Programa de Educação pelo Trabalho para a Saúde (PET-Saúde) da Universidade Estadual Vale do Acaraú (UVA) para notificação dos casos de violência registrados pela Delegacia da Mulher de Sobral em 2012 e 2013.

O PET-Saúde é uma estratégia do Governo Federal, com participação do Ministério da Saúde e do Ministério da Educação para fomentar a formação de grupos de aprendizagem tutorial em áreas prioritárias para o SUS, inserindo os estudantes das graduações em saúde nos espaços dos serviços. Esse projeto incentiva a integração entre ensino, serviço e comunidade, objetivando a interação com o cotidiano para a formação de profissionais cientes das necessidades dos serviços de saúde ${ }^{10}$. O PETSaúde na área de vigilância tem como objetivo atuar na área da vigilância epidemiológica a partir de vivências teóricas, práticas e de pesquisas relacionadas às doenças transmissíveis, não transmissíveis e agravos à saúde.

Deste modo, os integrantes do grupo tutorial do PET-Saúde fizeram o resgate das notificações de violência doméstica através dos dados contidos nos boletins de ocorrência da delegacia de defesa da mulher do município de Sobral e a partir de então realizaram a notificação dos casos de violência contra a mulher no SINAN-NET.

O estudo foi realizado no município de Sobral, no estado do Ceará, situado na região Noroeste do Estado do Ceará, com uma população de 188.233 habitantes, sendo 95.406 mulheres, segundo dados do censo do IBGE de $2010^{11}$.

A população foi composta pelas mulheres em situação de violência doméstica notificadas no SINAN-NET nos anos de 2012 e 2013. Vale ressaltar que, nesses dois anos, houve uma maior quantificação desse agravo em virtude do trabalho realizado pelo Programa de Ensino para - Trabalho em Saúde/Vigilância em Saúde (PET/VS) da Universidade Estadual Vale do Acaraú, quando os boletins de ocorrências de violência contra a mulher foram transformados em notificações e, posteriormente, digitados no SINAN- NET.

Foi utilizado como critério de inclusão: mulheres que sofreram violência no período de 2012 e 2013. Os critérios de exclusão foram: as notificações de violência no período estabelecido que não constassem os dados das variáveis: bairros de residência, bairro de ocorrência e hora da ocorrência da violência. Também foram excluídos os dados correspondentes aos distritos de Sobral. Inicialmente, a população foi composta por 1.138 mulheres, após a aplicação dos critérios de inclusão e exclusão, ela passou a ser de 965 mulheres.

O estudo foi desenvolvido no período de novembro de 2014 a dezembro de 2016 . A coleta de dados do presente estudo foi realizada na base local de dados do SINAN- NET, sob responsabilidade do Serviço de Vigilância Epidemiológica da Secretaria Municipal de Saúde de Sobral, mediante visitas ao Serviço de Vigilância Epidemiológica da Secretaria de Saúde de Sobral, bem como da consulta dos relatórios emitidos pelo TABWIN, aplicativo tabulador desenvolvido pelo DATASUS/MS para ser utilizado nas bases de dados dos Sistemas de Informação do SUS. Nessa perspectiva, as fontes documentais que foram utilizadas nesta pesquisa corresponderam aos dados da violência contra a mulher extraídos do SINAN- NET.

Para a análise dos dados, foram calculados alguns indicadores dessa violência, considerando os dois anos conjuntamente. Para o processamento e análise, os dados foram primeiramente armazenados e organizados em uma planilha eletrônica para análise estatística em cada ano.

Para alcançar os objetivos, foram utilizadas as seguintes variáveis: mês de ocorrência, faixa etária, escolaridade, local de residência e local de ocorrência, situação conjugal, tipologia da violência, meio de agressão, vínculo/ grau de parentesco com o agressor. A partir disso, foram realizadas análises exploratórias (descritivas) dos dados, por meio da apuração das frequências simples percentuais e absolutas para os campos categóricos, sendo estes, posteriormente, organizados em tabelas.

No que se refere ao mapeamento dos dados, utilizou-se o programa Quantum GIS 2.14, um software livre de geoprocessamento, tendo como unidade de análise o endereço de residência. Dessa forma, utilizou-se como referência o logradouro, o distrito sanitário e as coordenadas geográficas.

Em relação aos mapas construídos, utilizouse o mapa temático, que consiste em um método de visualização do comportamento espacial de determinados dados, sejam eles qualitativos ou quantitativos, tendo como referência uma variável gráfica como cor, forma, tamanho, distribuição em pontos (aglomerado, regular ou aleatório $)^{12}$. Infere-se, ainda, que foi utilizado paro o mapeamento, o shapefile (mapa da camada base) disponibilizado pela Secretaria do 
Planejamento, Desenvolvimento Urbano e Meio Ambiente do município de Sobral.

Este estudo obteve parecer favorável do Comitê de Ética em Pesquisa da Universidade Estadual Vale do Acaraú no mês de setembro de 2015, com o número de parecer: 1.229.524, sendo orientado a partir da Resolução de № 466, de 12 de dezembro de 2012, do Conselho Nacional de Saúde, que incorpora, sob a ótica do indivíduo e das coletividades, os quatros referenciais básicos da bioética: autonomia, não maleficência, beneficência e justiça, bem como visa assegurar os direitos e deveres que dizem respeito aos participantes da pesquisa, à comunidade científica e ao Estado ${ }^{13}$.

Enfim, foi realizada uma caracterização sociodemográfica dos casos, com a apresentação espacial de georreferenciamento das ocorrências da violência contra a mulher.

\section{Resultados e Discussões}

A partir da análise dos relatórios das fichas de notificação do SINAN- NET, pôde- se observar que, no ano de 2012, 495 mulheres estiveram inseridas em situação de violência e, no ano de 2013, esse quantitativo reduziu, totalizando 470 mulheres acometidas por esse agravo, o que representa um decréscimo de 5,05\% em sua ocorrência. Quanto ao período da ocorrência da violência, verificou-se o predomínio nos meses de janeiro com 12,3\% ( $n=119)$, seguidos de fevereiro, $11,2 \% \quad(n=108)$ e dezembro, 9,1\% $(n=88)$.

É relevante ressaltar que, o quantitativo elevado desses dois anos, é decorrente de uma atividade realizada pelo PET-Saúde. A partir disso, foi notável, após a análise dos dados, houve um aumento significativo do número de notificações registradas no SINAN-NET representando um aumento percentual de $819,05 \%(n=860)$ em comparação aos dados registrados antes da ação do PET, a qual é percebida pelo número de 105 violências notificadas nesse Sistema.

Mediante a avaliação das variáveis, caracterizaram-se as mulheres em situação de violência. Deste modo, foram analisadas 965 notificações nos dois anos do estudo, sendo a faixa etária mais prevalente de adultos jovens, de 20 a 39 anos, 58,4\% ( $n=289)$. Em relação à escolaridade, observou- se a predominância da resposta ignorada, $89,12 \% \quad(n=860)$. No que concerne à situação conjugal, a maioria eram casadas, $39,7 \% \quad(n=383)$ ou separadas $24,7 \%$ $(n=241)$, sendo constatado, também um percentual considerável de ignorado 16,3\% (n=158). Quanto à distribuição por local de residência, observou- se um predomínio dos bairros Sinhá Saboia e Dr. José Euclides, representando $16,5 \%(n=159)$ e $10,8 \% \quad(n=104)$, respectivamente locais já são conhecidos como áreas de risco para a criminalidade.

Em relação à caracterização dos agressores, representada na Tabela 1 , os resultados encontrados refletem que eles possuíam, em sua maioria, um vínculo afetivo com a mulher em situação de violência, sendo essa ligação representada em relação ao cônjuge 30,9\% $(n=298)$ e ex-cônjuge $29,8 \%(n=288)$. Quanto ao número de pessoas envolvidas na agressão $96,47 \% \quad(n=931)$ relaciona-se apenas a um agressor.

Tabela 1. Distribuição da frequência de agressores segundo número de envolvidos e vínculo de parentesco com a com a mulher em situação de violência, Sobral, Ceará, 2012 e 2013.

\begin{tabular}{ccc}
\hline Caracterização do Agressor & N & $\%$ \\
\hline Número de Envolvidos & & \\
Um & 926 & 95,96 \\
Dois ou mais & 39 & 4,04 \\
Vínculo & & \\
Pai & 21 & 2,2 \\
Mãe & 9 & 0,9 \\
Padrasto & 11 & 1,1 \\
Cônjuge & 298 & 30,9 \\
Ex-cônjuge & 288 & 29,8 \\
Filho & 69 & 7,1 \\
Irmão & 61 & 6,3 \\
Amigo/ conhecido & 46 & 4,8 \\
Desconhecido & 19 & 1,9 \\
Própria pessoa & 36 & 3,7 \\
Outros & 28 & 2,9 \\
Ignorado & 79 & 8,2 \\
\hline
\end{tabular}

Fonte: Sinan- Net 
Ao analisar a ocorrência da violência doméstica, foi possível identificar que 35,7\% ( $n=345)$ ocorrem nos horários de 18:00 às 23:59 horas, seguida do intervalo compreendido das $12: 00$ às $11: 59$ horas, $13,6 \% \quad(n=131)$. Com relação ao local da ocorrência, houve uma predominância acentuada dessa violência no âmbito da própria residência da mulher, totalizando $78,2 \%(n=755)$. No tocante ao tipo de violência, os dados revelam um predomínio da violência psicológica/ moral, 79,3\% ( $n=765)$ das notificações registradas no SINAN- NET, seguida da violência física com um percentual de 39,6\% $(n=382)$ das ocorrências. Este dado corrobora com o meio pelo qual a agressão foi efetivada, sendo $67,3 \%(n=650)$ deles por meio de ameaça e $32,4 \% \quad(n=313)$ através de força corporal/ espancamento.

Buscando visualizar a distribuição espacial dos dados, foram gerados mapas de cor para os anos de 2012 e 2013. Para a análise desses mapas, optou- se por separar as notificações em: antes do PET e pós-PET, a fim de realizar uma comparação da influência que esse programa fez em relação ao problema de subnotificação existente no SINAN-NET.

Por meio do cruzamento dos 105 dados pelo sistema Quantum GIS 2.14, foram identificados dez gradientes de densidade de violência contra a mulher, relacionados aos endereços de ocorrência desse agravo nos anos de 2012 e 2013. Foram classificados por cor, da mais escura para a mais clara, representando, dessa forma, o maior e o menor número de casos, respectivamente.

Considerando algumas modificações na conjuntura dos bairros do município de Sobral, eles foram condensados por distrito sanitário, a partir das divisões utilizadas pelo Serviço de Vigilância Epidemiológica de Sobral, Ceará. De acordo com a Figura 1, os distritos sanitários de maior incidência desse agravo, representados por cores mais densas foram: Sumaré, Centro, Sinhá Sabóia, Padre Palhano e Dr. José Euclides. Vale salientar que esse quantitativo refere- se às notificações existentes no SINAN-NET antes da intervenção do PET.

Figura 1. Distribuição Espacial dos Casos de Violência Contra a Mulher Notificados no SINAN-NET por Endereço de Ocorrência antes da Intervenção do PET.Sobral, Ceará, Brasil, 2017.

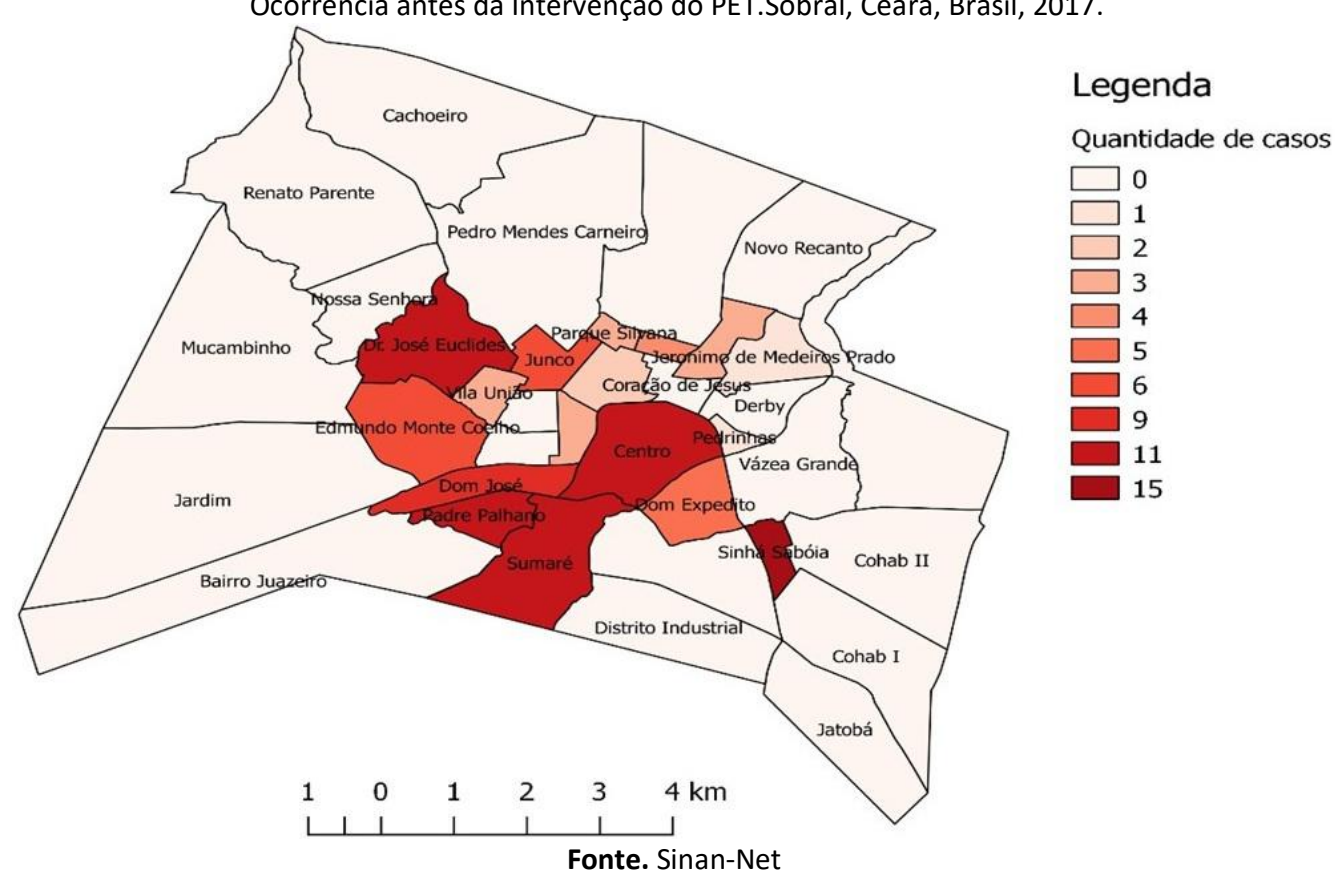

A Figura 2 representa a distribuição espacial dos casos por distrito sanitário de ocorrência após a intervenção do PET. A partir dele, observa-se uma maior concentração da ocorrência da violência doméstica nas legendas com gradientes mais densos: Sinhá Saboia, Centro, Dr. José Euclides, Centro e Dom José. A violência, por ser considerada um fenômeno social e histórico, sendo acompanhada por experiência da humanidade, torna-se um problema de saúde pública. Isso se deve ao fato de impactar diretamente na saúde individual e coletiva das pessoas. E, para sua prevenção e tratamento, exige formulação de políticas específicas e organização de práticas e de serviços peculiares ${ }^{14}$. 
Figura 2. Distribuição Espacial dos Casos de Violência Contra a Mulher Notificados no SINAN-NET por Endereço de Ocorrência após Internação do PETSobral, Ceará, Brasil, 2017

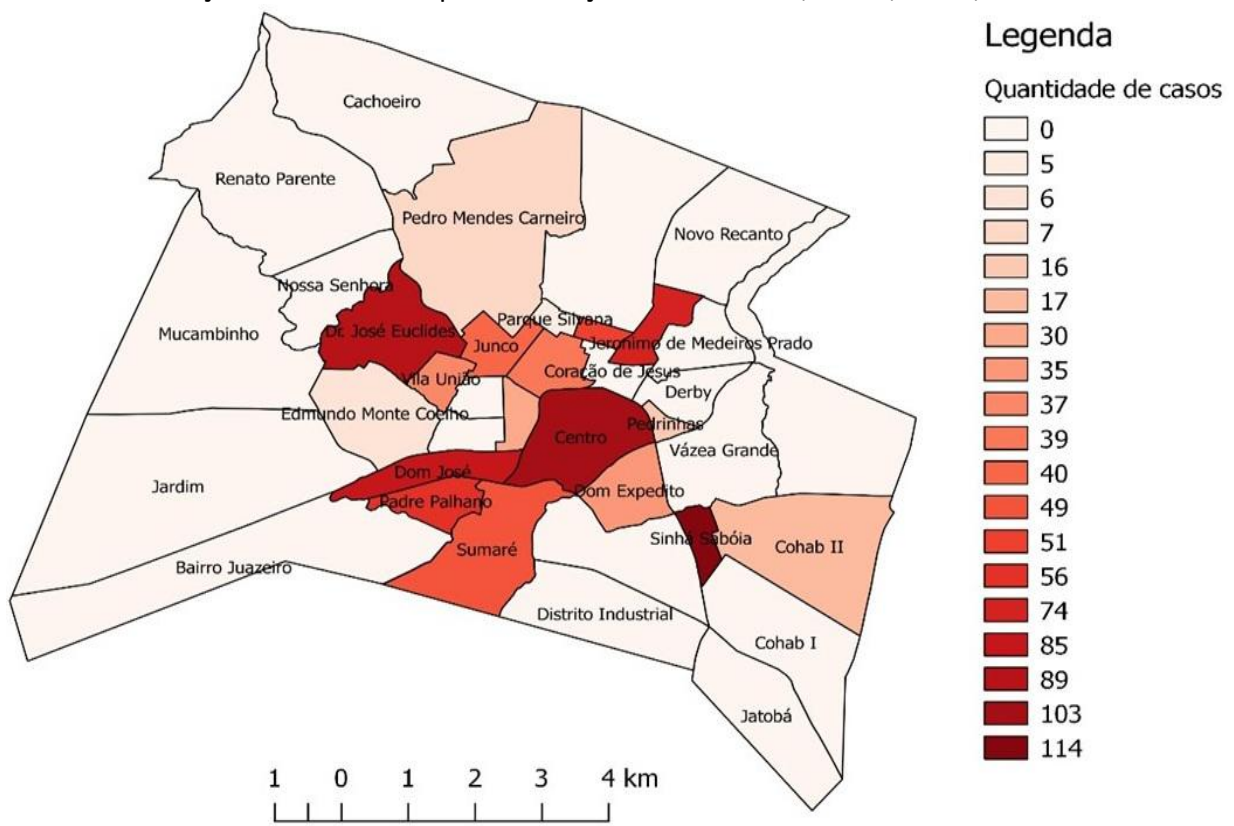

Fonte: Sinan-Net

Considerando os dados apresentados, pode-se afirmar que as maiores proporções de casos notificados foram identificadas entre mulheres adultas jovens. Isso significa dizer que a violência contra a mulher está presente em várias fases da vida, com maior expressão na idade adulta, o que pode ser explicado por se tratar de uma faixa etária na qual as mulheres são mais jovens e bonitas, além de possuírem uma vida social mais ativa e buscarem sua independência financeira, o que as torna vulneráveis a certos atos violentos por parte de desconhecidos ou ainda por ciúmes de parceiros ${ }^{2}$.

Outro aspecto relevante deve-se ao fato da variável escolaridade a qual apresentou-se predominantemente como ignorada. Isso faz refletir sobre a falta de algumas informações dos boletins de ocorrências, os quais influenciam de forma direta e negativa na qualidade dos dados colhidos. Considerando-se a incompletude, a formação mais apontada nos dois anos foi ensino fundamental incompleto, corroborando com outro estudo. É importante observar que, quanto menor o grau de escolaridade, menor é o acesso a informações, e isso influencia diminuindo a realização de denúncias ${ }^{15}$.

Além disso, os dados revelam como provável autor da agressão o cônjuge ou o excônjuge, ou seja, alguém que possui uma relação de proximidade com a mulher que sofreu a violência. Esse fato está intimamente relacionado com as desigualdades de gênero e dominação de homens em relação às mulheres nas relações afetivas, consequentes à naturalização dos atos de violência pela sociedade brasileira ${ }^{17,18}$.

No tocante à hora em que essas violências aconteceram, os dados da pesquisa revelaram que grande parte delas ocorreram no período da noite. No que concerne às características da ocorrência da violência, os dados analisados demonstraram que a residência foi o local mais frequente para a efetivação desse agravo. Outros locais também foram mencionados, tais como o ambiente da escola, locais de práticas esportivas, bares, via pública e comércios, mostrando-nos que a ocorrência da violência doméstica não está restrita ao domicílio.

Nessa perspectiva, estudos afirmam que os ambientes em que as violências contra a mulher mais ocorrem são na própria residência, chegando a $48 \%$ dos casos. $E$ mais, $41,61 \%$ das mulheres brasileiras agredidas foram violentadas no âmbito de suas relações domésticas, afetivas ou familiares, uma vez que, nesses casos, o sujeito ativo da agressão foi o cônjuge, o excônjuge ou parente ${ }^{19}$. Levando em consideração esses fatos, observa-se algo contraditório no que concerne à violência doméstica. Assim, fica claro que o local onde essas mulheres deveriam ter maior segurança, que é o ambiente familiar, torna- se palco das agressões sofridas por elas.

Em relação às diferentes formas de violência mais frequentes, destacaram-se as agressões psicológica e física, respectivamente. Esses dados reiteram o apresentado em estudos os quais apresentam a violência psicológica como 
de maior incidência. Em segundo plano, a violência física e, em terceiro, a violência sexual ${ }^{20}$.

Visto que a cidade configura-se como um espaço geográfico e geopolítico onde se produzem e se aplicam os conceitos e outros instrumentos de trabalho com potencial conservador/transformador da realidade, a elaboração e aplicação de políticas são oportunidades e momentos para essa prática social. Tais situações comportam diferentes enfoques metodológicos e requerem o emprego de uma multiplicidade de ferramentas que contribuam para a definição de prioridades e ampliação do acesso da população aos bens e serviços públicos.

Entre tais ferramentas, destaca-se a relevância da utilização do conhecimento da área do Geoprocessamento, especificamente o Sistema de Informações Geográficas (SIG), nos estudos sobre a distribuição espacial de problemas e análises de situações de saúde, como a violência doméstica contra a mulher ${ }^{21}$.

A análise espacial permitiu, neste estudo, identificar as vulnerabilidades de distritos sanitários, quanto à ocorrência desses agravos, constituindo-se como informação de grande importância para o processo de tomada de decisão, por meio de políticas públicas.

Os bairros de maior densidade se equipararam às áreas do município de menor poder aquisitivo, onde vivem as pessoas com condições mais precárias, de menor escolaridade, com exceção do distrito sanitário do Centro, o qual consiste em uma área mais evoluída economicamente em detrimento dos demais espaços analisados no estudo. A evolução das condições ambientais está fortemente influenciada pelas condições de saúde numa população, principalmente quando se configura a adequação das moradias e do saneamento do meio $^{22}$.

Além disso, a utilização da Análise Espacial da Violência Doméstica contra a mulher permitiu uma melhor visualização da ocorrência desse agravo, bem como evidenciou a existência de uma quantidade significativa de subnotificações existentes ao se comparar a Figura 1 com a Figura 2. Os dados da Figura 1 revelam o baixo índice de notificações realizadas no município do estudo.

Alguns fatores como o medo do envolvimento com o caso de violência justificam a subnotificação desse agravo. Entretanto, a notificação constitui- se como um instrumento essencial para a gestão municipal de saúde, uma vez que ela permite estimar a dimensão da magnitude dos casos de violência e, a partir disso, avaliar a necessidade de investimentos em núcleos de vigilância em saúde e serviços de assistência ${ }^{23}$.

Já na Figura 2, percebe-se o crescimento desses registros nos anos estudados, revelando, por meio dessa análise, a importância significativa da intervenção do PET-Saúde através do resgate dessas violências registradas em boletim de ocorrência na Delegacia de Defesa da Mulher de Sobral.

A partir disso, ressalta-se a importância das atividades de extensão universitária, na construção de um conhecimento acadêmico mais elaborado e possibilidade de democratização do saber e a participação da comunidade no ambiente científico ${ }^{24}$

Dessa forma, o PET é tido como articulador intersetorial entre Vigilância Epidemiológica e órgãos sentinelas, como a Delegacia de Defesa da Mulher durante o processo de resgate das notificações, proporcionando não só a aquisição de conhecimento em relação ao correto preenchimento da ficha de notificação, mas também, a conscientização a respeito da relevância em notificar esse agravo.

\section{Conclusão}

A partir da realização deste estudo, verificou-se um aumento bastante significativo do registro de notificações de violência contra a mulher no SINAN-NET após a intervenção realizada pelo PET. Além disso, também percebeu- se uma maior prevalência de mulheres jovens- adultas em situação de violência, com escolaridade ignorada. Percebeu-se também que um percentual considerável de mulheres casadas ou separadas. Os tipos de violências mais prevalentes foram a psicológica e a física e os bairros mais incidentes quanto à ocorrência desse agravo foram Sumaré, Centro, Sinhá Saboia, Padre Palhano e Dr. José Euclides.

Segundo os dados analisados, evidenciouse que a notificação desse agravo é marginalizada, visto que, a partir da intervenção do PET, é que foi possível visualizar, de modo mais efetivo, a verdadeira incidência da violência no município do estudo. É necessário ressaltar a importância de sensibilizar os diversos profissionais para a realização da notificação desses casos, bem como da existência de uma maior articulação intersetorial entre a saúde e a segurança pública a fim de evitar subnotificações e gerar resultados falsos. É neste ínterim que as atividades de extensão como o PET tornam-se essenciais para a efetivação dessa comunicação. Considerando a violência doméstica como um 
fenômeno complexo em decorrência de vários fatores, como a questão do gênero e dos determinantes sociais, ressalta- se a importância da articulação intersetorial como fator ímpar para esse problema, o qual deve ser encarado pelos diversos setores da sociedade para refletir a atual situação e, assim, pensar estratégias para reduzir sua ocorrência.

Além disso, ferramentas da área do Geoprocessamento, no caso, o Sistema de Informações Geográficas, são bastante importantes para subsidiar elaboração de planos e políticas públicas, onde o espaço como um território e seus determinantes sociais ampliam a variedade de situações territoriais sobre as quais precisa intervir para o enfrentamento de problemas e também para sua prevenção.

Os dados apresentados vão ao encontro da realidade percebida no município e, principalmente com a inquietação da maioria da população frente a essa problemática. Espera-se, com esta caracterização da violência doméstica, através da análise espacial das mesmas, incentivar a notificação e contribuir para a maior divulgação de informações que possam subsidiar a elaboração de políticas públicas integradas e intersetoriais e que efetivamente promovam a saúde e a qualidade de vida neste município.

\section{Referências}

1. Guimarães MC. A formação pessoal de psicólogos/as e o trabalho com violência doméstica contra a mulher. [recurso eletrônico]/ Maisa Campos Guimarães. Brasília, 2014. Disponível em: http://www.repositorio.unb.br/bitstream/10482/ 16657/1/2014_MaisaCamposGuimaraes.pdf.

2. Acosta DF, Gomes VLO, Barlem ELD. Perfil das ocorrências policiais de violência contra a mulher. Acta Paul Enferm 2013; 26 (6):547-53. Disponível em: http://dx.doi.org/10.1590/S010321002013000600007.

3. Guimarães MC, Perdoza RLS. Violência contra a mulher: problematizando definições teóricas, filosóficas e jurídicas. Psicologia \& Sociedade 2015; 27(2): 256-266. Disponível em: http://www.scielo.br/pdf/psoc/v27n2/18070310-psoc-27-02-00256.pdf

4. Almeida LR, Silva ATMC, Machado LC. O objeto, a finalidade e os instrumentos do processo de trabalho em saúde na atenção à violência de gênero em um serviço de atenção básica. Interface 2014; 18(48):47-59. Disponível em: https://www.scielosp.org/article/ssm/content/ra w/?resource_ssm_path=/media/assets/icse/v18n 48/1807-5762-icse-18-48-0047.pdf.

5. Pasinato W. Oito anos de Lei Maria da Penha: Entre avanços, obstáculos e desafios. Revista Estudos Feministas 2015; 23(2): 533-545. Disponível em: https://dx.doi.org/10.1590/0104026X2015v23n2p533

6. Brasil. Portaria no 104 de 25 de janeiro de 2011. Define as terminologias adotadas em legislação nacional, conforme o disposto no Regulamento Sanitário Internacional 2005 (RSI 2005). Diário Oficial da União 2011. Disponível em:

http://bvsms.saude.gov.br/bvs/saudelegis/gm/2 011/prt0104_25_01_2011.html.

7. Ribeiro MA et al. Georreferenciamento: ferramenta de análise do sistema de saúde de Sobral - Ceará. Sanare 2014; 13(2):63-69. Disponível em: https://sanare.emnuvens.com.br/sanare/article/ view/583/316.

8. Ribeiro, M.A. et al. Georreferenciamento: ferramenta de análise do sistema de saúde de Sobral - Ceará. Sanare. Sobral, v.13, n.2, p. 63-69, 2015. Disponível em: Acesso 17 outubro 2018.

9. Almeida FNM, Barreto ML. Desenho de Pesquisa em Epidemiologia. In:

Epidemiologia \& Saúde; fundamentos, métodos, aplicações. Rio de Janeiro: Guanabara Koogan, 2011.

10. Brasil. Ministério da Saúde. Ministério da Educação. Programa Nacional de Reorientação da Formação Profissional em Saúde - PRÓ-Saúde: objetivos, implementação e desenvolvimento potencial. Brasília, DF: Ministério da Saúde; Ministério da Educação, 2007. Disponível em: http://www.prosaude.org/rel/pro_saude1.pdf.

11. Brasil. Instituto Brasileiro de Geografia e Estatística. Censo Demográfico. Brasília, 2010.

12. Cellard A. A análise documental. In: Poupart J,organizador. A pesquisa qualitativa: enfoques epistemológicos e metodológicos. Vozes; 2008.

13. Brasil. Resolução № 466, de 12 de dezembro de 2012. Diretrizes e normas regulamentadoras de pesquisas envolvendo seres humanos. Conselho Nacional de Saúde. Brasília, DF; 2012. Disponível em: http://conselho.saude.gov.br/resolucoes/2012/r eso466.pdf.

14. Souto RQ, Leite CCS, França ISX, Cavalcanti AL. Violência sexual contra mulheres portadoras de necessidades especiais: perfil da vítima e do agressor. Cogitare Enferm 2012; 
17(1):72-77.

http://dx.doi.org/10.5380/ce.v17i1.26377.

15. SOUSA, A. K. A.; NOGUEIRA, D. A.; GRADIM, C. V. C. Perfil da violência doméstica e familiar contra a mulher em um município de Minas Gerais, Brasil. Cadernos de Saúde Coletiva, Rio de Janeiro, v.21, n.4, p.425-31, 2013. Disponível em: http://www.scielo.br/pdf/cadsc/v21n4/v21n4a1 1.pdf

16. Cecilio LPP, Garbin CAS, Rovida TAS, Queiróz APDG, Garbin AJl. Violência interpessoal: estudo descritivo dos casos não fatais atendidos em uma unidade de urgência e emergência referência de sete municípios do estado de São Paulo, Brasil, 2008 a 2010. Epidemiol Serv Saúde 2012; 21(2):293-304. DOI: http://dx.doi.org/10.5123/S1679-

49742012000200012.

17. Silva MCM, Brito AM, Araújo AL, Abath MB. Caracterização dos casos de violência física, psicológica, sexual e negligências notificados em Recife, Pernambuco, 2012. Epidemiol Serv Saúde 2013; 22(3):403-412. DOI: http://dx.doi.org/10.5123/S1679-

49742013000300005.

18. Brasil. Conselho Nacional de Justiça. O Poder Judiciário na aplicação da Lei Maria da Penha. Brasília. Diário Oficial da União 2013.

19. World Health Organization [Internet]. Global and regional estimates of violence against women: prevalence and health effects of intimate partner violence and non-partner sexual violence. 2013 [cited Out 10, 2018]. Available from: http://apps.who.int/iris/bitstream/10665/ 85239/1/9789241564625_eng.pdf

20. Lucena KDT, Silva ATMC, Moraes RMM, Silva CCS, Bezerra, IMP. Análise espacial da violência doméstica contra a mulher entre os anos de 2002 e 2005 em João Pessoa, Paraíba, Brasil. Cad Saúde Pública 2012; 28(6):1111-1121. DOI: $\quad$ http://dx.doi.org/10.1590/S0102311X2012000600010

21. Golding, J. Child health and environment. British Medical Bulletin, London 1986; 42:204211.

22. Silva A, Oliveira G. O registro das doenças de notificação compulsória: a participação dos profissionais da saúde e da comunidade. Rev Epidemiol Control Infect. 2014; 4(3):215-220.

23. Liliane L, et al. Extensão universitária e inclusão social de estudantes do ensino médio público. Trab Educ Saúde 2014; 12(3). DOI: http://dx.doi.org/10.1590/1981-7746-sip00003.

\section{Endereço para Correspondência}

Avenida Comandante Maurocélio Rocha Pontes no 186, Derby Clube, Sobral - CE

CEP.: $62042-280$

e-mail: isabellefrota2010@hotmail.com

Recebido em 07/07/2018

Aprovado em 26/10/2018

Publicado em 20/12/2018 